\title{
OS LIBERAIS ESPANHÓIS E A REVOLUÇÃO HISPANO-AMERICANA $1808-1823$
}

\author{
Earle Macarthy Moreira*
}

A tomada de poder pelos liberais peninsulares, quer na Espanha, quer em Portugal, tem como geratriz comum a invasão napoleônica e a guerra de libertaçâo dela decorrente.

Tendo-se em conta as circunstâncias do conflito, prolongado e sangrento, a evolução política dos acontecimentos não foi a mesma para as duas monarquias. Enquanto o Príncipe-Regente D. João de Bragança demandava o Brasil, com um séquito de cerca de 15.000 pessoas, nobres, funcionários, ministros, bibliotecas, coleçōes de artes, documentos importantes, riquezas particulares e da Coroa, mais como "feliz manobra política do que como deserção covarde", no dizer de Oliveira Lima - operação sem precedentes na história européia - resguardando aos olhos das demais potências a plenitude da soberania e a integridade do Império, os Bourbon de Espanha sujeitavam-se ao cativeiro e às humilhantes abdicações de Baiona.

Em nenhum momento, na premência de tão crítica situação, nem Carlos IV, nem Fernando VII, chegaram a considerar seriamente a hipótese de uma solução americana, embora tivessem à mão o "dictamen reservado" do Conde Aranda a Carlos III sugerindo que se desprendesse de todas as possessões do Novo Mundo, conservando unicamente Cuba e Porto Rico, na parte setentrional, e algumas outras na meridional, e que "colocara três infantes en América, el uno de Rey de México, el otro del Perú y el otro de los restantes de Tierra Firme"; que tomasse o título de imperador e recebesse anualmente, como supremo chefe da familia, tributos em prata, ouro e tabaco" "considerándose las cuatro naciones como una en cuanto el comercio reciproco". Esse projeto foi, a posteriori, refundido por Godoy e submetido a Carlos IV que, desconfiado com sobradas razбes da parentela, rechaçou-o. ${ }^{1}$ É possível que o comportamento de Napoleão em relação a 
outros monarcas europeus, relativamente benévolo, induzisse à crença de igual tratamento aoș reis espanhóis. Isso é o que se depreende do depoimento de Juan de Escóiquiz, participante ativo daquele drama:

"En vista pues, de estos hechos, que prueban el sistema constante de Napoleón, de no despojar del trono ni aun a sus enemigos, ihabia motivo para sospechar que lo variase y siguiese otro diametralmente opuesto con un rey aliado suyo, con una nación amiga, y que se habia sacrificado por él, con un joven monarca que no anelaba sino casarse con una princesa de su sangre?",

$\mathrm{O}^{\prime}$ que de modo algum foi levado em conta, a não ser quando era tarde demais, foi o peso específico das colônias americanas nos planos políticos do Imperador dos Franceses, segundo o relato do mesmo Escóiquiz, que as ouviu de viva voz;

“. . ; V. supone como infalible que la España perderá sus colonias; y yo, al contrario, tengo esperanzas muy fundadas de conservarlas. No crea $V$. que yo me he dormido. Tengo inteligencias en la América española." 3

O vazio de poder, decorrente dos episódios de Baiona, e todo o caso, propiciou à minoria liberal desempenhar um papel preponderante na seqüência dos acontecimentos; desde o estabelecimento de umas Cortes reformistas à elaboração de uma Constituição revolucionária, cujo embasamento popular era, no entanto, quase nulo.

Ramon Solís, em El Cádiz de las Cortes, considera a participação ativa do povo nas deliberaçóes como um mito, cuja base pode ser encontrada na narrativa novelesca de Benito Pérez Galdós (1843-1920), especialmente em um dos Episodios Nacionales intitulado Gadiz.

Escreve Solís:

"En un principio el pueblo vio en las Cortes un espetdiculo. (...) Pero el pueblo pronto se aburre de asistir a unos debates para los que no tiene formación ni preparación. (. . . ) Sin embargo, aunque los ciudadanos no asisten a los debates, siguen muy de cerca los comentarios de la prensa ... Es el periódico, podriamos decir, el único punto de contacto entre el pueblo y el Congresso". 
$\mathrm{O}$ próprio local das reuniøes era exíguo quanto à platéia; mal dava para acomodar cem pessoas e o número de espectadores nunca chegou à metade do de deputado.

O número total de deputados às Cortes não foi acima de 300 , com acentuada predominância de eclesiásticos, advogados, burocratas do Antigo Regime e militares: cerca de $80 \%$. Apenas oito congressistas eram comerciantes. ${ }^{4}$

Independentemente do fato, de per si injusto, da desproporcionalidade da representação dos territórios ultramarinos, muito inferior à metropolitana, o próprio curso da guerra dificultava o comparecimento às Cortes e o expediente encontrado para sanar o problema - tanto das colônias como territórios peninsulares sob ocupação inimiga - em agosto de 1810 , foi o de selecionar substitutos, entre os originários daqueles, lugares residentes em Cadiz. De 53 delegados substitutos, 30 corresponderiam à América. Na primeira reunião das Cortes, em 24 de setembro de 1810, dos 104 deputados presentes, 47 eram substitutos e 30 representavam o ultra-mar.

Às Cortes de 1812 acorreram 63 deputados americanos, perfazendo $21 \%$ do total. Dos 37 presidentes, 10 foram americanos. Não representavam a totalidade da população de seus países; apenas os brancos, "criollos" ou espanhõis, tinham direito a voto. As chamadas "castas" - mestiços, mulatos, gente de "color quebrado" - ficaram excluídas do processo eleitoral.

Solórzano, (Historia de la evolución económica de Guatemala), serve para exemplificar o que isso significa numericamente: a população da Capitania Geral da Guatemala, nessa época, era composta de 600.000 índios, 300.000 mulatos, negros e "castas" e de, aproximadamente 50.000 bran$\cos ^{5}$

A questão da proporcionalidade foi um dos grandes obstáculos que, desde janeiro de 1809, quando a Junta Central convocou representantes americanos, até a plena consumação do processo independentista, frustrou as tentativas de um acordo entre a Metrópole e os rebeldes deste continente; muito embora, o ato em si haja sido o primeiro movimento relevante, no sentido de igualar os direitos políticos dos cidadáos de ambas as partes da Monarquia.

Outra dificuldade, jamais solucionada, dizia respeito à liberdade de indústria e comércio; de modo que, entre um discurso ideológico que proclamava a liberdade e a igualdade americanas, e o sentimento generalizado, no ambiente peninsular, de que era impossível sonhar com um futuro de grandeza abdicando-se do estatuto colonial, prevaleceu, num primeiro momento, a primacial condição de serem espa ahóis em estado de guerra; e, após a vitória, o ônus da reconstrução, que não podia abdicar dos recursos 
da América. Em suma: o liberal espanhol, por liberal não deixava de ser espanhol; e, nas circunstâncias da crise, até mesmo mais espanhol que liberal.

As cifras aportadas pelo Conde de Toreno, recém entrado na casa dos vinte anos então e protagonista destacado daquelas Cortes, em sua História del levantamiento, guerra y revolución de Espãna, não deixam margem a dúvidas: de 28 de janeiro a 31 de outubro de 1810 a tesouraria da Regência registrou ingressos no valor de 351 milhões de "reales de vellón”, sendo provenientes da América 195 milhões, ou seja 55,5\%. Mesmo depois, quando em 1811 a contribuição americana cai para $35 \%$ do total arrecadado, em conseqüência dos movimentos insurreicionais, ainda assim era indispensável para o sustento de uma força armada de mais de 100.000 homens na Península. ${ }^{6}$ Forçoso é, portanto, convir com Timothy. E Anna, (España y la Independencia de América): "Las necesidades económicas habrian de determinar la politica en relación con América."?

À luz do que se tem estudado sobre o papel desempenhado pelos liberais espanhóis, no que se pode chamar de a questão americana no primeiro período constitucional, não é descabido admitir-se que por sua própria condição de minoria, atuante é bem verdade, mas predominantemente composto de gente jovem e imatura, a peso da herança de uma "Ilustração" despojada de sua ideologia própria e reduzida a um programa de reformas empíricas, no marco da ordem política e social existentes, não haja deixado a sua marca. Especialmente, na concepção de uma América reformada administrativa, econômica e politicamente mas, como diz R.A. Humphreys: “. . . imperial reform meant binding America closer do Spain and making it a more fruitful source of wealth and power". 8

E não há como negar a existência, velada na maior parte das vezes, declarada e aberta raramente, de um profundo sentimento de frustração, de raiva mesmo, em relação às reivindicações do ultramar, por inoportunas ou despropositadas. $\mathrm{O}$ exemplo mais flagrante desse estado de espírito nos é dado pelo famigerado memorial do Consulado do México, lido na sessão das Cortes de 16 de setembro de 1811 e que terminou selado e arquivado. O retrato que ali se pinta dos habitantes das colônias é, no mínimo, repelente. $\mathrm{O}$ índio era "estúpido por constitución, sin talento inventor ni fuerza de pensamimento, aborrece las artes y oficios, borracho por instinto..., carnal por vicio de la imaginación ... desnudo de ideas puras sobre la continencia, pudor o incesto". Os mestiços, "ebrios incontinentes, flojos sin pundonor, agradecimiento ni fidelidad . . ., sin aseo, ni decencia, parecen aun más maquinales y desarreglados que aun el indio mismo". E os "criollos", "los blancos indigenas juegan, enamoran, beben y visten en pocos dias, las herencias, dotes y adquisiciones que debian regalarlos toda su vida" e depois se consolam "con sueños y trazas de la independencia que 


\section{ha de conducirlos a la dominación de las Américas"."}

Desgraçadamente, facécias de mau gosto, indagações propositadmente imbecis, deboches, etc., de que não se eximia o próprio lider dos liberais, Argüelles, (e não tinha a desculpa da pouca idade, verão que era de mais de 30 anos), documentam o indisfarçável ressentimento reinante entre os representantes peninsulares nas Cortes de Cádiz. (Cf. Memoria de Baquíjano, conde de Vistaflorida, Madrid, 11/8/1814).

Assiste razão a Charles Kingsley Webster quando se refere a que "the French Revolution in its Napoleonic expression" pode com propriedade ser vista como "the greatest of all the forces which made a revolution in Lat in A merica inevitable". A falta de comunicações com a Metrópole, invadida e ocupada pelos exércitos napoleônicos a partir de 1808 , bem como o repúdio a José Bonaparte, levam as colônias americanas a um movimento revolucionário próprio, de modo que quando as Cortes chegam a reunir-se, este já se encontrava em marcha acelerada. ${ }^{10}$

$\hat{E}$ certo que, num primeiro momento, o movimento desembocou no reconhecimento da soberania de Fernando VII e no apoio aos poderes constituídos que, na Metrópole, faziam frente aos franceses. O estabelecimento da Junta Central e seus projetos reformistas, dos quais logo deu bom exemplo declarando a igualdade entre espanhóis e hispano-americanos, bem como convocando Cortes e, pela primeira vez na história, deputados das colônias, contribuiu para contemporizar a situação; porém, a invasâo da Andaluzia e a dissolução da Junta Central repercutiram muito mal na América, lançando o movimento especificamente seccionista com a formação de Juntas locais, as quais, embora reconhecendo a soberania de Fernando VII, passaram a ignorar a Regência e a substituir os agentes da administração por elementos adictos à causa autonomista. Conforme Miguel Artola:

\section{"La fórmula casi uniforme que servió para llevar a cabo el asalto al poder fue la reunión de cabildos, abiertos, en los que los elementos independentistas pudieron apoyar- se para constituir gobiernos que suplantaron a las autori- dades españolas." "11}

A evolução dos acontecimentos no Rio da Prata confirma essa assertiva. Depois das tentativas golpistas de 1809 e da chegada do vice-rei Cisneros, designado pela Junta Central como elemento de conciliação, difundem-se as notícias dos fracassos bélicos na Península. Cria-se um clima de desassossego geral. Cisneros é obrigado a convocar um "cabildo abierto" - 
("Puesto que el pueblo no me quiere y el ejército me abandona, hagan ustedes lo que quieran.") - e o resultado foi que dentre 250 concorrentes só 2 votaram por sua permanência. Os espanholistas do corpo capitular tentam desconhecer essa resolução, mas são forçados pelas armas. Nasce assim a "Junta de Maio", presidida por Saavedra (25/5/1810).

O partido americano aproveitando-se, portanto, das circunstâncias internacionais, toma de assalto o poder. Ressentimentos acumulados estão presentes nessa ação; mas, também foi a expressão de um setor que visava romper com as peias monopolistas, nisto sendo acompanhado por muitos espanhóis, que por interesses de classe, a ele se vinculavam.

É como expressa Washington Reyes Abadie:

"Los hombres que integraron, el 25 de mayo de 1810, la denominada "Junta Provisional Gubernativa de las Provincias del Río de la Plata, a nombre del Señor Don Fernando VII", conocida como "Junta de Mayo", eran una calificada representación del patriciado porteño que, de tiempos atrás, esperaban el "momento" - como diría Saavedra en sus Memorias para tomar el poder." 12

O fato é que, naquela hora, os próprios "criollos" fernandearam, com boa dose de convicção. Defender os direitos do rei era entrar na liça por uma causa popular, tanto na Espanha como na América. Era a defesa da Monarquia Nacional, que não significava depender mais da Metrópole, pois governar em nome de um monarca ausente era governar com independência de quaisquer Juntas ou Conselhos, que na mãe-pátria se pudessem formar. Quaisquer que hajam sido as divergências a respeito do verdadeiro significado do vocábulo "independência" - se dentro ou fora da monarquia nacional - em torno de uma meta comum havia pleno consenso: auto-governo e comércio livre.

Diante do verdadeiro programa de reformas ventiladas desde Baiona, medíocres tornam-se as vantagens obtidas pelos deputados americanos em Cadiz. O descontentamento, que vinha de longe, aumentou com a injusta desproporção das representaçб̃es nas Cortes, tendo-se em conta a população das colônias: cerca de 13 milhôes de habitantes na América para 10,5 milhōes na Península, isto sem falar nas Filipinas. Um deputado americano para cada 100.000 brancos, em contraposição a um peninsular por cada cidade que houvesse tido um voto nas Cortes anteriores (1789), um por cada junta provincial e um por cada 50.000 habitantes, não era o que se pode chamar de representação equitativa.

As distinçб̄es conferidas a deputados americanos - participação em comissões, presidências ou regências - não passaram de meros atos gratulatórios. Afinal, a Constituição de 1812, verdadeiro coroamento da obra das 
Cortes de Cadiz, seguiu um modelo unitário e centralista, fazendo caso omisso das realidades, das peculiaridades próprias do Novo Mundo. Nela nâo se encontra sequer uma referência especíçfica à América, como algo diferente da Metrópole. Na visão de Timothy E. Anna o "error fundamental de los liberales fue ciertamente que, lo mismo que los conservadores, apenas parecian reconocer la existencia separada de América. El éxito de la Constitución pudo haberse alcanzado si hubiera reconocido algunas de las complejas diferencias en la sociedad, en la economia, en las costumbres $y$ hasta en la geografía, que tanto distinguian a la América española. Era una Constitución europea para una España europea". ${ }^{13}$

Se houve um ponto comum entre absolutistas e liberais, que a essa altura já estavam em pé de guerra, este foi o da resistência e hostilidade declarada às aspiraçôes autonomistas dos povos americanos; o que motivou a taxativa declaração de Jaime Delgado: "Pero hubo un factor español más transcendental y decisivo en el ulterior separatismo americano: la absoluta falta de comprensión de los gobernantes españoles." 14 Se dessa falta de compreensão se fez réu Fernando VII, tão logo dissolveu as Cortes e restaurou o absolutismo, dela igualmente não se eximem os liberais "doceañistas" que fraudaram as esperanças neles depositadas pelos hispano-americanos. Em ambos os casos o problema do relacionamento entre a Espanha e a América terminou sendo objeto de uma solução de força, de uma linha política dura, acompanhadas hipocritamente de um palavrório vão de concórdia, que contribui mais ainda para o acirramento dos ânimos.

Descartados os anos de intensa repressão patrocinados por Fernando VII, cujo nível moral - dirá Gregório Marañón - "pocas veces podrá reproducirse en la estirpe de los Jefes de Estado, con tal suma de felonia y maldad", ${ }^{15}$ anos em que os liberais não tiveram voz nem voto e quando a simples suspeita de liberalismo tornou-se crime; a "questão americana", por ironia do destino, assegurou-lhes um retorno triunfal à cena política, embora breve. A 1 o de janeiro de 1820 , em “Cabezas de San Juan", D. Rafael de Riego e as tropas destinadas a lutar contra os rebeldes americanos, sublevam-se, restauram a Constituição e provocam a primeira fissura na estrutura conservadora e absolutista da Europa da Santa Aliança. Instaura-se o "Triênio Liberal".

Uma testemunha dos acontecimentos, Andrés Borrego, anos depois, registrou este depoimento:

“.. los inválidos que regresaban de Venezuela al desembarcar en las costas del litoral gaditano, andrajosos, hambrientos, inutilizados y escarmentados, ponderaban 
su mala ventura y decian a voz en grito a los acantonados expedicionarios que les esperaba igual suerte si sobrevivian al adverso destino que iban a buscar ... En cuanto a los oficiales, asi entre ellos como entre los paisanos, era general la opinión de que el restablecimiento de la Constitución de 1812 allanaría el antagonismo de los criollos y abriría la puerta a la pacificación de aquellas regiones y a una era de sólidas ventajas, tanto para los americanos como para los españoles. "16

Também o escritor e político português Almeida Garret guardou na lembrança o eco daquela jornada:

"Que perspectiva para a raça humana! Que esperanças! Liberdade sem sangue, igualdade sem desavencas, religião sem fanatismo, monarquia sem despotismo, nobreza sem oligarquia, governo popular sem demagogos!',17

O entusiasmo, porém, não obnubilou o entendimento daquele grande político e escritor, que percebeu logo duas das gretas principais da revolução:o "pronunciamento" e a abstenção popular. Dirá:

“Certo é que sem o auxilio da for ca armada era impossivel qualquer revolução no estado daqueles paises. Mas fazer-se do que só devia ser auxílio, agente único e exclusivo, eis ai o grande, o máximo, o capital erro das revoluções peninsulares de 1820. Todos os homens ilustrados, todos os cidadãos honrados aplaudiram e adotaram de coração e alma os principios (as formas, nem todos) do sistema proclamado; mas a massa geral, o corpo da nação, que nunca se decide sem ver, tocar, palpar por si mesma, ficou impassivel e pela maior parte indiferente." 18

As forças armadas consolidarão, ao longo do tempo, o regime liberal mas, em troca, tornar-se-ฮ̃o o poder dirimente, com as seqüelas inevitáveis do caudilhismo militar.

Intentaram os liberais, no breve tempo em que detiveram as rédeas do governo, sanear a economia e as finanças públicas mediante três medidas básicas: 1 ? uma reforma agrária, aliás, utópica; 2 9 a centralização administrativa e fiscal; 30 uma abertura ao capital estrangeiro, no caso, francês. 
Serão, no entanto, incapazes de impor um clima de paz e de ordem no país, sem o qual todas as boas intençбes e medidas progressistas não chegaram a desbordar dos limites do papel em que foram estampadas.

A situação da Espanha, já no ano seguinte ao episódio revolucionário, é descrita por Mesonero Romanos nas suas Memorias de un setentón:

“. . al terminarse el año 21, segundo del periodo constitucional, la situación del país no podia ser más aflictiva. Los partidos extremos, exaltados y absolutistas, desplegaban al viento sus banderas; el monarca, en abierta pugna con el Gobierno, y éste desprestigiado y vencido también en la opinión; las Cortes, moderadas y prudentes, cediendo el paso a las nuevamente elegidas, en que dominaba el elemento "exaltado", sin que los diputados $y$ honrados patriotas que compusieron las primeras pudieran ser reelegidos, según la Constitución; las sociedades secretas, onipotentes hasta entonces, divididas y debilitadas por sus contrarias tendencias; la prensa periódica desatenta y sin freno, contribuyendo a crear una atmósfera mefítica de extravio revolucionario; $y$ para que nada faltase a este sombrio cuadro, la fiebre amarilla paseando nuestros pueblos de la costa desde Cádiz a Barcelona; y colocado, en fin, en la frontera del Pirineo, bajo el titulo de "cordón sanitario", un ejército, que amenazaba transformarse en ejército "de observación", $y$ más tarde en el "de ocupación", encargado de realizar los acuerdos sucesivos de Troppau, de Laiback y de Verona."19

O já citado Andrés Borrego dá o veredito sobre o Triênio Liberal:

"Grande e inmensa fue, sin duda, la gloriosa iniciativa que tomó la España liberal, levantando ante la Europa absolutista la bandera de la liberdad democrática; pero para sostenerla con probabilidades de que no sucumbiese, preciso habria sido que hubiésemos tenido detrás de nosotros a la nación, o en su defecto haber producido en beneficio del pueblo un cambio en su bienestar, realizando mejoras tan positivas y palpables que de ellas alcanzasen las clases menesterosas, supliesen a la escasa autoridad que las ideas alcanzaban y de la que desgraciadamente careciamos todavia por lo general en España." $8^{20}$ 
Quem se dá ao trabalho de estudar o comportamento dos homens do "Triênio" em relação aos fatos da América não deixa de perceber como estavam mal informados ou mal preparados para enfrentá-los. Sem dúvida, naqueles três anos em que dançavam de braços dados a euforia e a angústia, a audácia e a falta de bom senso, o atropelo e o medo, seria difícil ver as realidades com clareza e definir políticas coerentes. Mas, por outro, resulta difícil entender a sua manifesta incapacidade para absorver os fatos consumados: a Batalha de Maipu (5.4.1818); o Congresso de Angostura e o surgimento da Grã Colômbia (fevereiro de 1819); o triunfo de Bolívar em Boyacá (7.8.1819); a chegada da expedição de San Martin ao Peru, em setembro de 1820, e o abandono da Venezuela por Morillo, em dezembro; a derrocada do vice-rei Pezuela no Peru, o "Plan de Iguala" de Iturbide, o triunfo de Bolívar em Carabobo, a independência do México e da América Central, em 1821; no ano seguinte a derrota realista de Pichincha e a independência do Equador.

Ignorar a devida importância de tudo isso e esperar que a notícia da reconstitucionalização metropolitana e um generoso convite a partticipar das Cortes, impoliticamente acompanhado da ameaça de que em caso de recusa continuariam a sofrer as agruas da guerra e estariam expostos a "los terribles efectos de la indignación nacional", reconduzissem os rebeldes americanos ao redil, é, no mínimo, a demonstração cabal da mais completa falta de competência para quem se arvora em governo. ${ }^{21}$

É provável que só o fracasso dos emissários aportados a Montevidéu, em 19 de novembro de 1820 - o coronel Manuel Herrera, D. Tomás Comyn e o capitão de fragata Manuel Martín Mateo embarcados no bergantim Aquiles, no seu contacto com a Junta de Representantes das Províncias Unidas, nos primeiros dias de dezembro, haja começado a impor a plena consciência de que qualquer negociação entre as partes em litígio haveria de passar, necessariamente, pela preliminar e indispensável base do reconhecimento da independência que as províncias haviam proclamado em congresso geral, segundo a ata que lhes foi dada, e "de cuyo sagrado compromisso ante el Eterno y ante las naciones del globo, no pueden separarse un punto sin renunciar a sus más altos e incontestables derechos". ${ }^{22}$ Mas, como o pior cego é o que não quer ver, em sua chegada à Espanha, nos primeiros dias de agosto de 1821, ainda tiveram o atrevimento de atribuir o seu insucesso a "los dos fuertes adversarios con que se les habia destinado a luchar": a intriga estrangeira e a anarquia doméstica. ${ }^{23}$

Em janeiro de 1822, a questão volta à baila nas Cortes, onde já então crescia o número dos partidários de um reconhecimento da independência das colônias, uma vez que o curso da guerra ñ̃o dava margem a alimentar 
esperanças, além do prejuízo que a situação estava causando à economia metropolitana.

Em um informe às Cortes constava que era o caso de "aprovechar el tiempo que aun se tenia para asegurar a España algunos derechos de preferencia para su comercio; y salvar en A mérica las propriedades y capitales de un gran numero de Españoles, amenazados de una completa expoliación". ${ }^{24}$

Nova tentativa de reconciliação é feita. A 13 de fevereiro de 1822 são designados novos emissários para a América. Com destino ao Rio da Prata, seguem Antonio Luis Pereira, ministro da Audiência do Chile, (na oportunidade, desempenhando funçбes consulares no Rio de Janeiro) e o tenente-coronel Luis de la Robla.

A chegada dos comissionados a Montevidéu ocorreu a 29 de abril, mas só passaram a Buenos Aires em 23 do mês seguinte. Resultou do encontro com as autoridades portenhas uma controvertida convenção, que provocou sérias restriçóes de Mariano Moreno no que se referia ao pagamento de uma subvenção à Espanha, a título de indenização: "sonaria $\infty$ mo tributo".

Reinava geral desconfiança quanto às verdadeiras intençōes da tal missão, sendo que para muitos não passava de manobra visando obter uma trégua a fim de permitir à Espanha recuperar suas forças, com vistas à reconquista. Félix Alzaga, nomeado pela Junta de Buenos Aires para obter a adesão do Chile, Peru e Colômbia ao acordo, não encontrou maior receptividade. Quando Las Heras é mandado ao Peru, com a mesma finalidade, chega a notícia da tomada de Cadiz pelas tropas do Duque de Angoulême e do fim do governo constitucional. Com isso cessavam os poderes dos emissários e ficavam anulados todos os seus atos, encerrando-se, assim, o episódio.

O que o mundo assistiu depois foi uma repressão tão violenta aos liberais espanhóis, que chegou a assustar o próprio Luís XVIII, obrigando-o até a advertir a S.M.C. de que não havia sido esse o objetivo da ajuda que lhe acabava de prestar. Os moldes em que a mesma se efetuou foram trágicos e odiosos. 0 populacho, açulado por agitadores e escorado na complacência das autoridades, excedeu-se nos desmandos. Nas aldeias e mesmo nas cidades maiores, pessoas incriminadas de militância liberal ou simplesmente suspeitas eram espancadas; os homens tinham os bigodes e a barba arrancados a força; as mulheres eram tosquiadas e emplumadas. Tribunais de exceção passaram a julgar sumariamente as acusações de conspiração; somente entre 24 de agosto e 12 de setembro de 1823 houve, entre enforcamentos e fuzilamentos, 112 execuçఠes. A pena de morte não escaparam 
sequer os menores de 18 anos. São referidos, com freqüência, nas "memórias" e histórias do século passado, casos como este: um sapateiro, por ter o retrato de Riego na parede de seu quarto, foi condenado a dez anos de prisão, não sem antes ter desfilado até o local da forca com o corpus delicti dependurado no pescoço. No patíbulo, o carrasco, devidamente paramentado e com toda a solenidade, cremou a efígie anatematizada. A mulher do malfadado remendão, por cúmplice, pegou dez anos de galera e o filho de ambos, pelo mesmo motivo, dois anos de cadeia.

"Hay períodos en la história - escreverá em 1875 Zamora y Caballero na sua História General de España - que un escritor pasaria por alto con mucho gusto, para ahorrar-se la indignación y la vergüenza de tener que referir los sucesos ocurridos en ellos. Uno de estos períodos es el de la reacción absolutista que siguió en España a la caída del sistema constitucional en 1823."25

Concluindo: A Península Ibérica, ao contrário do restante da Europa onde o movimento liberal batia em retirada, acompanhando os despojos das legiōes napoleônicas, justamente nessa hora foi o que viu vitorioso dentro de suas fronteiras. A euforia do momento, acompanhada de uma visão otimista do futuro e de uma devoção - quase religião - constitucional, levou os homens de Cadiz a perseguir o milagre de uma reforma política, desconsiderando as realidades estruturais, sócio-econômicas, da Espanha e de seu Império.

O movimento de independência da América Espanhola é um capítulo singular dessa etapa revolucionária e é nessa filiação que podemos distinguir com maior nitidez os seus contornos, as suas peculiaridades, as suas idiosincrasias. Tendo cmo fatores geradores próximos as circunstâncias criadas pela Guerra Peninsular, tal movimento abeberou-se na mesma fonte do idealismo gaditano, mas tomou rumos próprios.

As atitudes das Cortes, tímidas e receosas de dar "demais" aos povos do Novo Mundo, comprometeram as possibilidades de um entendimento mútuo. À grandeza das idéias não correspondia a dos estadistas. Tanto os "doceañistas" como os "veintenos" revelaram-se curtos de vista na abordagem dos problemas hispano-americanos. 
NOTAS

1Apud GOICOECHEA, A. - La politica internacional de España en noventa años. Madrid, Publicaciones de la Real Academia de Jurisprudencia y Legislación, pp. 2632.

${ }^{2}$ ESCOIQUIZ, Juan de. - "Idea sencilla de las razones que motivaron el viaje del Rey Don Fernando VII a Bayona en el mes de abril de 1808", in Memorias de tiempos de Fernando VII, 1. Madrid, Biblioteca de Autores Españoles, n ${ }^{0}$. 97, 1957, pp. 193-197. Vide: ANNA, Timothy E. - España y la independencia de América. México, FCE, 1986 , Cap. I.

3 -. "Memorias", p. 132. Idem. Ibid.

${ }^{4}$ SOLIS, Ramón. - El Cádiz de las Cortes. Madrid, Alianza, 1969. (2ª ed.), pp. 237 243.

${ }^{5}$ Apud TUÑON DE LARA, Manuel. - La España del siglo XIX. Barcelona, Laia, 1973 , p. 33.

${ }^{6}$ TORENO, Conde de. (José Marra Queipo de Llano Ruiz de Saravia). - Historia del levantamiento, guerra y revolución de España. Madrid, Biblioteca de Autores Españoles, no 64,1953 . p. 396 ss.

${ }^{7}$ ANNA, España ... op. cit., p. 116.

${ }^{8}$ HUMPHREYS, R. A. \& LINCH, J. - The origins of the Latin American revolutions, 1808-1826. New York, A. A. Knopf, 1966, p. 10.

${ }^{9}$ HERNÅNDEZ Y DÁVALOS, Juan E. - Colección de documentos para la historia de la Guerra de Independencia de México, 6v. México, José María Sandoval, 18771882. 2:450-466. Cf. ANNA, España ... op. cit.,pp. 106-107.

${ }^{10}$ WEBSTER, C. K. (Ed.) - Britain an the independence of Latin America, 1812 1830. 2v. London, 1938. 16-12.

${ }^{11}$ ARTOLA, Miguel. - La burguesía revolucionaria (1808-1869). Madrid, AlianzaAlfaguara, 1973, p. 38. (Historia de España Alfaguara, V).

${ }^{12}$ REYES ABADIE, Washington. - Artigas y el federalismo en el Río de la Plata, 1811-1820. Montevideo, Ed. Banda Oriental, 1974, p. 7. (Trad. do A.)

${ }_{13}^{13}$ ANNA, España . . . op. cit., pp. 109-110.

${ }^{14}$ DELGADO, Jaime. - La independencia hispanoamericana. Madrid, Instituto de Cultura Hispánica, 1960, p. 57.

${ }^{15}$ MARANON, Gregorio. - "Prólogo", in SOLIS, El Cádiz . . . op. cit. p. 19.

${ }^{16}$ BORREGO, Andrés. El general Riego y los revohucionarios liberales. In: La España del siglo XIX. Madrid, Ateneo, 1885-1886, pp. 332-333.

${ }^{17}$ GARRET, J. B. Almeida. - Portugal na balança da Europa. Reed. Lisboa, Horizonte, (s.d), (1. ed. 1830), p. 69.

${ }^{18}$ GARRET, Portugal . . . op. cit., p. 70.

${ }^{19}$ MESONERO ROMANOS, Ramón de. - Memorias de un setentón. Madrid, Inst. Espaffola y Americana, 1880, cap. XI. Vide: GARCIA NIETO, M.C. et alii. Bases documentales de la España Contemporánea, 1:128-129.

${ }^{20}$ BORREGO, El general Riego ... op. cit., p. 355 .

${ }^{21}$ Gaceta de Buenos Aires, 27.09.1820.

${ }^{22}$ BELGRANO, Mario. La polltica exterior del Gobierno de Martin Rodrigues. El re- 
conocimiento de la independencia. In: LEVENE, Ricardo. (Ed.) - Historia de la nación argentina, VI:521-526. B. Aires, Imp. de la Universidad, 1936-42.

${ }^{23}$ BELGRANO, La polttica... op. cit., loc. cit.

${ }^{24}$ BELGRANO, La politica... . op. cit., pp. 527 ss.

${ }^{25}$ ZAMORA Y CABALLERO, P. E. - Historia general de España y de sus posesiones de ultramar. Madrid, Est. Tip. de J. A. Mufioz, 1875, t. 6, p. 401.

- Pontifícia Universidade Católica do RGS

Curso de Pós-Graduação em História

90.620 - Porto Alegre - RS. 